Blair D Goranson FRCPC, *

Scott Lang FRCPC,

J. David Cassidy PHD, ${ }^{\dagger}$

William N Dust FRCsC, ${ }^{\dagger}$

Jeff McKerrell FrCsc ${ }^{\dagger}$

\section{A comparison of three regional anaesthesia techniques for outpatient knee arthroscopy}

Purpose: The purpose of this study was to compare intraoperative conditions and postoperative pain control of three peripheral regional anaesthesia techniques for outpatient knee arthroscopic procedures.

Methods: Sixty patients were randomized to one of three groups. Group IA received portal injections $(10 \mathrm{ml}$ lidocaine $1 \%)$, intraarticular lidocaine $\left(20 \mathrm{ml} \mathrm{CO}_{2}\right.$ lidocaine $2 \%$ with I/200,000 adrenaline) and a placebo femoral nerve block ( $20 \mathrm{ml}$ saline). Group FNB received a femoral 3 -in-1 nerve block $(20 \mathrm{ml}$ chloroprocaine $2 \%$ with $1 / 200,000$ adrenaline). placebo portal injections ( $10 \mathrm{ml}$ saline) and placebo intraarticular saline $(20 \mathrm{ml}$ saline with 1/200.000 adrenaline). Group FNB + IA received a femoral 3 -in-I nerve block, intraarticular lidocaine and placebo portal injections. The following were assessed: intraoperative pain $(10 \mathrm{~cm}$ VAS: $0=$ no pain, $10=$ extreme pain), surgical operating conditions ( $1=$ excellent, $4=$ unacceptable), intraoperative use of sedation and analgesia, time to discharge, patient satisfaction score $(1=$ very satisfied, 5 very unsatisfied) and postoperative anaigesia. Data were analyzed using ANOVA, Kruskal-Wallis, and Chi-square tests as appropriate. $P<0.05$ was considered significant.

Results: There were no differences among the groups regarding any of the variables tested. Considerable postoperative pain (VAS 25) was experienced by 20/54 (37\%) patients.

Conclusion: Any of the three anaesthetic techniques tested provide reliable intraoperative patient and surgical conditions for outpatient knee arthroscopy. Patient discomfort postoperatively was considerable in all groups and requires further investigation.

Objectif : Cette étude visait à comparer les conditions peropératoires et l'analgésie postopératoire procurées par trois techniques périphériques d'anesthésie régionale administrées pour une chirurgie arthroscopique du genou chez des patients ambulatoires.

Méthodes : Soixante patients étaient répartis aléatoirement en trois groupes. Le groupe IA recevait des injections portales $(10 \mathrm{ml}$ lidocaine $1 \%)$, de la lidocaïne intra-articulaire $\left(20 \mathrm{ml}\right.$ de lidocaïne $\mathrm{CO}_{2}$ adrénalinée à $\left.1: 200000\right)$ et un bloc fémoral placebo. Le groupe FNB recevait un bloc fémoral 3 dans 1 ( $20 \mathrm{ml}$ de chlorprocaine $2 \%$ adrénalinée à 1:200 000), une injection portale placebo (10 $\mathrm{ml}$ de sol. phys.) et une injection articulare placebo de sol. phys. (20 ml de sol. phys. adrénaliné à $1: 200000$ ). Le groupe FNB + $\mid A$ recevait un bloc fémora 3 dans 1 , de la lidocaine intra-articulaire et des injections portales placebo. Les paramètres suivants étaient évalués : la douleur peropératoire (ÉVA $10 \mathrm{~cm}: 0$ = pas de douleur, $10=$ douleur extrême), les conditions chirurgicales ( 1 = excellentes. 4 = inacceptables), l'utilisation peropératoire de sédation et d'analgésie, le score de satisfaction du patient (I = très satisfait, 5 = très mécontent) et l'analgésie postopératoire. Les tests pertinents ANOVA, Kruskal-Wallis et chi au carré ont servi à l'analyse des données. $P<0,05$ était considéré comme significatif.

Résultats : II n'y a eu aucune différence au regard des variables étudiées. Vingt patients sur 54 (37\%) ont éprouvé une douleur postopératoire importante (ÉVA 25 ).

Conclusion : Les trois techniques étudiées ont procuré des conditions opératoires favorables à une arthroscopie du genou tant pour le patient ambulatoire que pour le chirurgien. Linconfort postopératore était considérable et devrait susciter des études plus approfondies.

From the Departments of Anaesthesia* and Orthopaedics, ${ }^{\dagger}$ Royal Universiry Hospital, Saskatoon City Hospital, University of Saskatchewan, Saskatoon, Saskatchewan S7N OW8, Canada.

Address correspondence to: Dr. S A Lang, Department of Anacsthesia, Royal University Hospital, 103 Hospital Drive, Saskatoon, Saskatchewan S7N OW8.

Actepted for publication Janunry 11, 1997. 


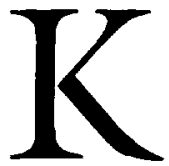

NEE arthroscopy and arthroscopic surgery is often done using peripheral regional anaesthesia techniques. ${ }^{1-4}$ Peripheral regional anaesthesia techniques have included intraarticular local anaesthetic, ${ }^{1}$ combined psoas compartment and sciatic nerve blocks, ${ }^{2}$ and femoral 3 -in-1 nerve blocks. ${ }^{3}$ Gencral anaesthesia ${ }^{5}$ and major neuraxial anaesthesia ${ }^{6-8}$ (spinal, epidural, and combined spinal-epidural techniques) are also commonly used for knee arthroscopic procedures. The variety of techniques may reflect investigator and clinical bias or inherent limitations of each technique. Most of our orthopaedic surgeons use intraarticular local anaesthesia for outpatient knee arthroscopic surgery. However, a small group of them have, until recently, continued to perform these procedures under general or spinal anaesthesia because of perceived inadequacies of the intraarticular local anaesthetic technique. In response to these concerns a new technique was developed which combined intraarticular lidocaine with a femoral 3 -in-1 nerve block to try to improve surgeon and patient acceptance of regional anacsthesia for outpatient knee arthroscopy. ${ }^{9}$ Outpatient knee arthroscopic procedures at our institution take an average of $35 \pm 14$ min (mean $\pm S D)^{9}$ of operating room time. A technique that would conform to this time frame and not take too long to perform or subject the patient to a prolonged recovery would seem ideal. Innervation of the knee is supplied by the femoral, lateral femoral cutaneous, obturator, and sciatic nerves. The investigators hypothesized that if neural blockade of the femoral, lateral femoral cutaneous and obturator nerves were accomplished with a femoral 3-in-1 nerve block using a short acting local anaesthetic (2-chloroprocaine) and additional coverage for the articular sensory fibres of the sciatic nerve was supplied with intraarticular lidocaine, the perceived inadequacies of intraarticular lidocaine alone could be overcome. We were successful in convincing these surgeons to convert to the use of the combined technique for knee arthroscopic surgery. However, these same surgeons were not convinced that this initial success was due to the advent of a "new" anacsthetic technique. They felt that they may simply have become accustomed to performing knee arthroscopy under local anaesthesia. Therefore, this study was designed to determine if any of three peripheral regional anaesthesia techniques currently used for knee arthroscopy in our institution (i.e., femoral 3-in1 nerve block, intraarticular lidocaine, and a combination of both techniques) provided better intraoperative patient or surgical conditions or postoperative pain control.

\section{Methods}

After Institutional Review Board approval and informed consent, 60 patients were randomized to one of three groups (Table I) by random number table. Patients scheduled for elective operative or diagnostic knee arthroscopy on an outpatient basis at the Royal University Hospital and Saskatoon City Hospital were included in the study. Patients were excluded if they were inpatients or were scheduled for emergency surgery. Group IA (IA-intraarticular) received portal ${ }^{a}$ injections (10 ml lidocaine $1 \%$ ), intraarticular lidocaine ( $20 \mathrm{ml} \mathrm{CO}_{2}$ lidocaine $2 \%$ with $1 / 200,000$ adrenaline) and a placebo femoral 3 -in-1 nerve block $(20 \mathrm{ml}$ normal saline). Group FNB (FNB-femoral nerve block) received a femoral 3 -in-1 nerve block ( $20 \mathrm{ml}$ chloroprocaine $2 \%$ with $1 / 200,000$ adrenaline), placebo portal injections ( $10 \mathrm{ml}$ normal saline), and a placebo intraarticular injection $(20 \mathrm{ml}$ normal saline with $1 / 200,000$ adrenaline). Group FNB+IA (combined femoral nerve block and intraarticular lidocaine injection) received a femoral 3-in-1 nerve block with chloroprocaine, intraarticular lidocaine, and placebo portal injections. Portal sites were identified with a marker by the surgeon in the holding area. Femoral 3-in-1 nerve blocks were performed using a $5 \mathrm{~cm}, 22 \mathrm{G}$ Teflon insulated needle (Stimax, Becton Dickinson, Rutherford, New Jersey) and a nerve stimulator (Digistim II, Neurotechnology, Houston, Texas). Chloroprocaine or saline was injected after a brisk quadriceps motor response was elicited at $\leq 0.2 \mathrm{mamp}(1 \mathrm{~Hz}, 200 \mu \mathrm{sec}$

TABLE I Characteristics of patients undergoing arthroscopic knee surgery. ${ }^{1}$

\begin{tabular}{lccc}
\hline Variables * $^{*}$ & $\begin{array}{c}\text { Group IA } \\
(n=20)\end{array}$ & $\begin{array}{c}\text { Group FNB } \\
(n=19)\end{array}$ & $\begin{array}{c}\text { Group FNB+IA } \\
(n=20)\end{array}$ \\
\hline Sex $(\mathrm{M} / \mathrm{F})$ & $9 / 11$ & $15 / 4$ & $11 / 9$ \\
Age $(\mathrm{yr})$ & $41.1 \pm 16.5$ & $44.9 \pm 15.8$ & $36.4 \pm 14.5$ \\
Height $(\mathrm{m})$ & $1.68 \pm 0.1$ & $1.73 \pm 0.1$ & $1.67 \pm 0.1$ \\
Weight $(\mathrm{kg})$ & $87.1 \pm 23.4$ & $87.6 \pm 8.0$ & $79.4 \pm 3.9$ \\
Duration $(\mathrm{min})^{\dagger}$ & $27.4 \pm 21.1$ & $24.2 \pm 13.6$ & $26.6 \pm 15.5$ \\
Procedure $(\mathrm{op} / \mathrm{dx})^{\ddagger}$ & $6 / 14$ & $5 / 14$ & $6 / 14$ \\
\hline
\end{tabular}

1 Table values are counts or means \pm SD.

* There were no significant differences in any variables among groups.

$\uparrow$ Duration of operation.

† Procedure operative (op) or diagnostic (dx).

$\mathrm{IA}=$ intraarticular, $\mathrm{FNB}=$ femoral nerve block, $\mathrm{FNB}+\mathrm{IA}=$ femoral nerve block and intraarticular

\footnotetext{
a Local anaesthetic is infiltrated, following cutaneous and subcutaneous injection at a portal site previously marked by the surgeon, all the way to and through the joint capsule.
} 
pulse width). Intraarticular injections were made through the lateral superior patellar portal site with an $18 \mathrm{G}$ needle. All patients received $1 \mathrm{mg}$ alfentanil iv prior to the performance of any local infiltration or nerve block. All patients were monitored with pulse oximetry and received supplemental oxygen during the performance of the blocks. All anaesthetic procedures were performed in an induction room by an anaesthetist not participating in the operative care of the patient or in data collection (thus double-blinding the study). Blocks were performed 10-15 min before the patients were moved to the operating theatre. Prior to entering the operating room the anaesthetist who performed the block assessed the adequacy of surgical conditions (these were the only data collected by the block anaesthetist). Patients in the FNB and FNB+IA groups had their femoral 3-in-1 nerve blocks assessed with a sharp pin. Patients in the IA group had a "mock" assessment of the sensory distributions of the femoral, lateral femoral cutaneous, and obturator nerves performed with a blunt cannula. In addition, patients in the IA group had their portal sites assessed with a sharp pin. The "block" anaesthetist supplemented (lidocaine $1 \%)$ any portal sites that were found not to be analgesic to pin prick before transfer of the patient to the operating room. Tourniquets were not used. All patients received supplemental oxygen intraoperatively and were monitored with pulse oximetry, ECG, and blood pressure. Intraoperative sedation and analgesia were restricted to midazolam and fentanyl given at the discretion of the operative anaesthetist who was unaware of the group assignment. Any time sedation or analgesia was given the reason $(s)$ for administration were recorded. Patients were advised that they could and should ask for sedation or analgesia at any time. Intraoperatively the following were assessed: intraoperative pain $(10 \mathrm{~cm}$ horizontal linear visual analogue scale -VAS, $0=$ no pain and $10=$ extreme pain), intraoperative use of sedation and analgesia, and surgical operating conditions $(1=$ excellent, $2=\operatorname{good}, 3=$ moderate, $4=$ unacceptable). Intraoperative assessment of pain was performed every $15 \mathrm{~min}$ or when the patient experienced a painful event (e.g., trochar insertion) or requested sedation or analgesia. In addition, at the end of the surgery the patient was asked to estimate their overall pain experience on a $10 \mathrm{~cm}$ VAS. Surgical operating conditions were assessed by the primary surgeon at the end of surgery. Local anaesthetic supplementation by the surgeon or conversion to general anaesthesia was recorded. Individual cumulative doses of fentanyl and midazolam were tabulated. Surgical times were recorded. The type of procedure (operative or diagnostic) was recorded.
The patients were transferred to the recovery room from the operating room. They were discharged home when they could ambulate independently (motor power was assessed by the recovery room nurse every $15 \mathrm{~min}$ by straight leg raising followed by the ability to do deep knee bends). Discharge time was defined as the time from entering the recovery room until discharged home. No attempt was made to discharge the patients as soon as possible using strict criteria. Rather, the nurses were allowed to discharge patients according to their regular practice pattern as long as the patient could ambulate independently.

A postoperative mail survey was sent home with each patient. Patients were asked to assess their overall discomfort (10 cm VAS) 12 and 24 hr postoperatively. Severe postoperative pain was arbitrarily defined as a VAS $\geq 5$. In addition, patients were asked to estimate their overall satisfaction with their entire perioperative experience on a 5 point scale $(1=$ very satisfied, 2 = satisfied, 3 = somewhat satisfied, $4=$ unsatisfied, 5 $=$ very unsatisfied).

Results are presented as means $\pm S D$ where appropriate. Data from our pilot study ${ }^{9}$ were used to perform an $a$ priori power analysis to estimate the required sample size $(\alpha=0.05, \beta=0.20$, clinically significant difference in maximum VAS scores defined as 23 , standard deviation \pm 1.5$).{ }^{10}$ Data were checked for assumptions of normality and homogeneity of variance (Levene statistic). Parametric (ANOVA), nonparametric (KruskalWallis), and categorical (Chi-square) tests were used appropriately. Alpha was set at 0.05 .

\section{Results}

One patient (group IA) was excluded from analysis because of admission to hospital for the control of postoperative pain and bleeding (medial meniscus repair for a locked knee). Surgical conditions were rated very good to excellent in all groups. Patient satisfaction was excellent in all groups. There was no difference in the number of patients in groups FNB or FNB+IA who required additional local anaesthetic supplementation due to an incomplete femoral 3 -in-1 nerve block before going to the operating room (5/20 patients in each group - no patient in the IA group required supplementation). There were no differences in the distribution of surgeons or surgery among the groups. Maximum intraoperative VAS scores did not differ among groups (Table II), (Figure 1). There were no differences among groups in the administration of supplementary intravenous fentanyl and midazolam. The discharge times of three patients were not recorded (group IA; two patients and group FNB; 1 patient). Six patients failed to return their postoperative surveys (group IA, three patients; group 


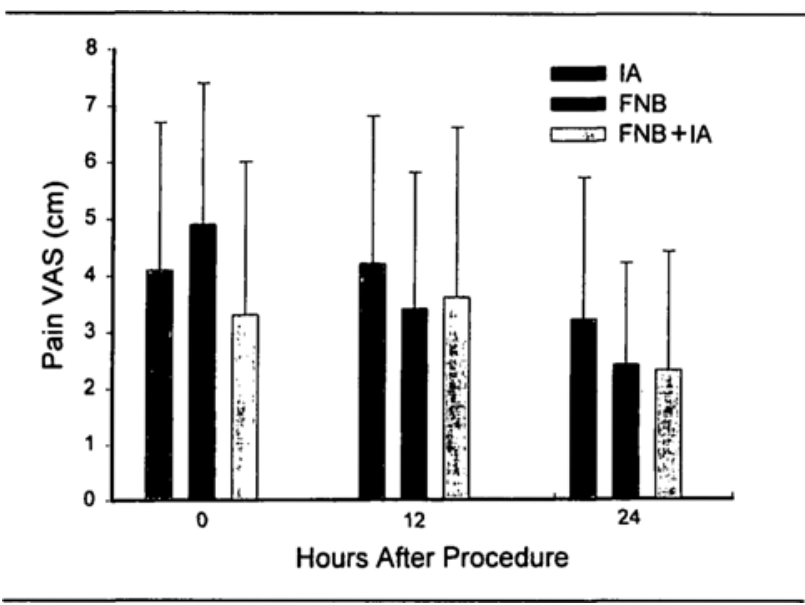

FIGURE 1 Intraoperative and Postoperative Pain Scores $0=$ intraoperative pain scores (maximum recorded VAS)

$12=12 \mathrm{hr}$ postoperative pain scores (mail survey)

$24=24 \mathrm{hr}$ postoperative pain scores (mail survey)

$\mathrm{IA}=$ intraarticular group

FNB $=$ femoral nerve block group

$\mathrm{FNB}+\mathrm{IA}=$ femoral nerve block and intraarticular group

FNB, one patient; and group FNB+IA, two patients). There was no difference among the groups in surgical or discharge times. The pooled average (standard deviation) surgical time was $26.1 \pm 16.9 \mathrm{~min}$ and discharge time was $143.1 \pm 70.1 \mathrm{~min}$. There was no difference among the groups in the amount of postoperative pain they experienced (Table II), (Figure 1). However, patients in all groups experienced significant (as defined) pain at home (17/54-31\% - patients at $12 \mathrm{hr}$ and $10 / 54-19 \%$ patients at $24 \mathrm{hr}$ ). There were no complications related to the anaesthetic techniques but one patient in group FNB required conversion to general anaesthesia.

\section{Discussion}

An ideal anaesthetic for outpatient arthroscopic knee surgery ${ }^{11}$ would be technically simple to administer, have a rapid onset and a high success rate, allow early discharge, have few or no side effects, be inexpensive, and help provide postoperative pain control. Ideally, the technique chosen would also allow the patient the option of viewing their arthroscopy on a video screen. ${ }^{12,13}$ Regional anaesthesia techniques have the potential to fulfill these criteria.

Producing complete anaesthesia of a lower extremity with a combination of nerve blocks has many limitations for rapid turnover outpatient knee arthroscopies. Many anaesthetists are not familiar or comfortable with the techniques used. ${ }^{14,15}$ It takes considerably more time to perform more than one nerve block (usually a combination of femoral 3 -in-1 and sciatic nerve blocks). ${ }^{2,16}$ The combined failure rate is increased when
TABLE II Outcomes in patients undergoing arthroscopic knee surgery. ${ }^{1}$

\begin{tabular}{lccc}
\hline Variables $^{*}$ & $\begin{array}{c}\text { Group IA } \\
(n=20)\end{array}$ & $\begin{array}{c}\text { Group FNB } \\
(n=19)\end{array}$ & $\begin{array}{c}\text { Group } F N B+I A \\
(n=20)\end{array}$ \\
\hline Trochar insertion VAS & $2.7 \pm 2.1$ & $2.6 \pm 2.7$ & $1.9 \pm 2.0$ \\
Maximum VAS & $4.1 \pm 2.6$ & $4.9 \pm 2.5$ & $3.3 \pm 2.7$ \\
12 hour VAS & $4.2 \pm 2.6$ & $3.4 \pm 2.4$ & $3.6 \pm 3.0$ \\
24 hour VAS* & $3.2 \pm 2.5$ & $2.4 \pm 1.8$ & $2.3 \pm 2.1$ \\
Fentanyl ( $\mu$ g) & $\mathbf{5 7 . 5} \pm 56.3$ & $90.8 \pm 72.8$ & $50.0 \pm 56.2$ \\
Midazolam (mg) & $1.0 \pm 1.3$ & $0.9 \pm 0.8$ & $0.8 \pm 1.3$ \\
Discharge time (min) $)^{\dagger}$ & $117 \pm 47$ & $149 \pm 43$ & $162 \pm 98$ \\
Patient satisfaction $\ddagger^{*}$ & $1.4 \pm 0.5$ & $1.8 \pm 0.9$ & $1.4 \pm 0.6$ \\
Surgical conditions $^{\$}$ & $1.5 \pm 0.6$ & $1.9 \pm 1.0$ & $1.5 \pm 0.7$ \\
\hline
\end{tabular}

${ }^{1}$ Mean \pm SD.

* Mail survey: Group IA, n=17; Group FNB, n=18; Group FNB + IA, $n=18$.

† Discharge time: Group IA, n=18; Group FNB, n=18; Group

$\mathrm{FNB}+\mathrm{IA}, \mathrm{n}=20$.

$\ddagger$ Graded from 1 (very satisfied) to 5 (very unsatisfied).

$\checkmark$ Graded from 1 (excellent) to 4 (unacceptable).

IA $=$ intraarticular, FNB $=$ femoral nerve block, FNB + IA $=$ femoral nerve block and intraarticular

There were no significant differences in any variables among groups.

multiple nerve blocks are performed. ${ }^{17}$ Inevitably, then, there will be operative delays when these techniques are used for short surgical procedures. In addition, a totally anaesthetic extremity may be undesirable at the end of the surgery and may delay discharge (PADS or Postanaesthesia discharge scoring system). ${ }^{18}$ The only saving grace is the possibility that nerve blocks may help provide better postoperative analgesia. ${ }^{19}$

Therefore, we decided to explore the utility of nerve blocks that do not provide a completely anaesthetic limb and the use of local infiltration and intraarticular local anaesthesia for use in knee arthroscopic surgery. These techniques have the potential to provide all of the goals of the ideal anaesthetic. Patel $e t a l^{3}$ described the use of the femoral 3-in-1 and lateral femoral cutaneous nerve blocks for knee arthroscopy and compared these techniques with general anaesthesia. They found that femoral 3-in I nerve blocks (especially when combined with a separate lateral femoral cutaneous nerve blockLFCN) provided excellent operative conditions, patient satisfaction, and allowed earlier discharge than a group of patients given general anaesthesia: However, they excluded all patients believed to need posterior knee joint manipulation which indicates that they felt not all arthroscopic patients were ideal candidates for local anaesthesia. ${ }^{12,13}$

Local anaesthetic infiltration of portal sites combined with instillation of intraarticular local anaesthetic has been described by a number of investigators for use in knee arthroscopic surgery. ${ }^{1,12}$ However, concerns about the adequacy of the surgical conditions provided by this 
technique have been raised. ${ }^{13}$ Some of our surgeons also expressed similar concerns including the following; patient discomfort during the procedure (particularly on manipulation of the posterior aspect of the joint), technical difficulty and restricted access due to poor muscle relaxation and muscle spasm, increased patient anxiety, intraarticular bleeding, and cutaneous anaesthesia restricted to predetermined portal sites. Therefore, we sought to develop an alternative technique that would overcome some of the perceived limitations of the intraarticular local anaesthetic technique (IA). ${ }^{9}$ We hypothesized that a combination of a femoral 3-in-1 nerve block and intraarticular local anaesthetic would provide more complete anaesthesia of the knee than the utilization of either local anaesthetic infiltration of portal sites and intraarticular anaesthesia or a femoral 3-in-1 nerve block alone. The femoral 3-in-1 nerve block would anaesthetize the femoral, lateral femoral cutaneous, and obturator nerves thereby providing anaesthesia for all the portal sites as well as intraarticular anaesthesia. The addition of the intraarticular local anaesthetic would supply the remainder of the necessary intraarticular anaesthesia by blocking terminal nerve fibers supplied by the sciatic nerve. In a pilot study we demonstrated the feasibility of this technique and its efficacy in a group of surgeons unaccustomed to performing knee arthroscopy under local anaesthesia. ${ }^{9}$ However, our surgeons felt that the success we experienced with our new technique may have been due to greater familiarity and acceptance of local anaesthesia for knee arthroscopy rather than due to the enhanced efficacy of our new technique. ${ }^{20}$ Therefore, we designed this study to investigate the utility of local anaesthesia for outpatient knee arthroscopy and to compare the relative efficacy of three peripheral regional anaesthesia techniques. We did not exclude any patient who consented to the study from participation as we wished to assess the general efficacy of the regional anaesthesia techniques for both diagnostic and surgical knee arthroscopies. The surgical conditions provided by the FNB+IA technique and the FNB technique were no better than in the IA group and there were no differences among the groups with regard to intraoperative analgesia, sedative or analgesic use, side effects, discharge, or patient satisfaction. Therefore, the performance of an isolated femoral 3-inI nerve block or the addition of a femoral 3-in-1 nerve block to intraarticular local anaesthetic did not seem to confer any clinical intraoperative advantage relative to the IA technique alone. A post-hoc power analysis of our intraoperative data yielded a power of 0.92 (ANOVA; three groups; $\Delta$ mean maximum VAS [defined arbitrarily $]=3$; mean standard deviation [from Table II] $=2.6$; $\mathrm{n}=20 ; \alpha=0.05$ ).
Concern about prolonged motor blockade in the FNB groups led us to use chloroprocaine $2 \%$ with $1 / 200,000$ adrenaline for the nerve blocks. All patients were ambulatory before discharge and there were no differences among the groups in discharge times. However, this observation may simply reflect the practice pattern of the nurses in the recovery rooms at the two study institutions as there was no attempt to regulate discharge of patients beyond the insistence that they be able to ambulate independently.

We had hoped that the femoral 3 -in-1 nerve blocks might confer an advantage to groups FNB and FNB+IA in the postoperative period in the form of enhanced analgesia. However, we found that there was no difference in the severity of the pain reported by patients in any group and there was no difference in analgesic consumption. However, the power of these observations is limited because of the dropouts experienced in the mail survey. Overall, considerable postoperative pain (arbitrarily defined as VAS $z 5$ ) was experienced by $37 \%$ of patients postoperatively.

In conclusion, we have found that all three peripheral regional anaesthesia techniques examined in this study provided excellent surgical conditions in outpatients for either diagnostic or surgical arthroscopies. The performance of an isolated femoral 3-in-1 nerve block or the addition of a femoral 3-in-1 nerve block to intraarticular local anaesthetic does not improve operating conditions or confer better postoperative analgesia when compared with the use of intraarticular local anaesthetic alone. After completing this study we concluded that, because of its simplicity and effica$c y$, the intraarticular administration of lidocaine should be the technique of first choice for routine diagnostic and surgical arthroscopies of the knee.

\section{Acknowledgments}

We wish to acknowledge the help of the members of the Departments of Anaesthesia and Orthopaedics at Royal University Hospital and City Hospital, Saskatoon, Saskatchewan. We also wish to thank Pat Henick for her help in collecting the data and the secretaries of the Department of Anaesthesia, Royal University Hospital, for their assistance in the preparation of this manuscript.

\section{References \\ I Dabl MR, Darta JF, Zuelzer W, McSweeney TD. Lidocaine local anesthesia for arthroscopic knee surgery. Anesth Analg 1990; 71: 670-4. \\ 2 Farny J, Girard M, Drolet P. Posterior approach to the lumbar plexus combined with a sciatic nerve block using lidocaine. Can J Anaesth 1994; 41: 486-91.}


3 Patel NJ, Flasbburg MH, Paskin S, Grossman R. A regional anesthetic technique compared to general anesthesia for outpatient knee arthroscopy. Anesth Analg 1986; 65: 185-7.

4 Anapolle DM, Badach M, McInerney VK, Umanoff $M$, Ghobadi $F$. Knee arthroscopy using regional nerve blockade. Orthopedic Review 1994; 23: 449-52.

5 Smith I, Newson CD, White PF. Use of forced-air warming during and after outpatient arthroscopic surgery. Anesth Analg 1994; 78: 836-41.

6 Dabl JB, Schultz P, Anker-Moller E, Christensen EF, Staunstrup HG, Carlsson P. Spinal anaesthesia in young patients using a 29-gauge needle: technical considerations and an evaluation of postoperative complaints compared with general anaesthesia. $\mathrm{Br} J$ Anaesth 1990; 64: 178-82.

7 Siler $J N$, Rosenberg $H$. Lidocaine hydrochloride versus lidocaine bicarbonate for epidural anesthesia in outpatients undergoing arthroscopic surgery. J Clin Anesth $1990 ; 2: 296-300$.

8 Urmey WF, Stanton J, Peterson M, Sharrock NE. Combined spinal-epidural anesthesia for outpatient surgery. Anesthesiology 1995; 83: 528-34.

9 Goranson $B D$, Lang $S A$, Dust WN. Combined femoral 3 in 1 nerve block and intra-articular local anesthesia for knee arthroscopy. Reg Anesth 1995; 20 : S29.

10 Cohen J. Statistical Power Analysis for the Behavioural Sciences. 2nd ed. Hillsdale: Lawrence Erlbaum Associates, 1988: 273-403.

11 Parnass $S M, M c$ Carthy $R J$, Bach BR Jr, et al. Beneficial impact of epidural anesthesia on recovery after outpatient arthroscopy. Arthroscopy 1993; 9: 91-5.

12 Yacobucci GN, Bruce R, Conaban TJ, Kitz DS, Tory JS. Arthroscopic surgery of the knee under local anesthesia. Arthroscopy 1990; 6: 311-4.

13 Fairclough JA, Graham GP, Pemberton D. Local or general anaesthetic in day case arthroscopy? Ann $R$ Coll Surg Engl 1990; 72: 104-7.

14 Kopacz DJ, Bridenbaugh LD. Are anesthesia residency programs failing regional anesthesia? The past, present, and future. Reg Anesth 1993; 18: 84-7.

15 Still $A$, Mabendru V, Fu E, Derasari M, Downs JB. Adequacy of resident training in regional anesthesia and pain medicine. Anesth Analg 1996; 82: S428.

16 Lang S. Posterior lumbar plexus block (Letter). Can J Anaesth 1994; 41: 1238-9.

17 Lang S, Yip RW. Lack of volume dependency of the femoral 3-in-1 nerve block when utilizing a nerve stimulator. Anesth Analg 1994; 78: S236.

18 Chung F. Discharge criteria - a new trend. Can J Anaesth 1995; 42: 1056-8.
19 Tetzlaff JE, Yoon HJ, Brems J. Patient acceptance of interscalene block for shoulder surgery. Reg Anesth 1993; 18: 30-3.

20 Fruensgaard $S$, Johannsen HV. Outpatient arthroscopy of the knee under local anaesthesia. Int Orthop 1990; 14: $37-40$. 